\title{
Analysis of Architectural Art of Traditional Ancestral Hall in Ji' an Meibei Village, Jiangxi Province
}

\author{
Li Yanjun ${ }^{1,}$, Sun Xingzhi ${ }^{2, b^{*}}$ \\ ${ }^{I}$ Shaanxi University of Science \& Technology, Xi'an, Shaanxi, 710021 \\ ${ }^{2} X i$ 'an University of Technology, Xi'an, Shaanxi, 710054 \\ aylw55668@163.com \\ b*645390865@qq.com

\begin{abstract}
Ji 'an area in jiangxi province of traditional architecture with its style of primitive simplicity, elegant atmosphere, distinct, strewn at random have send, structure compact, dao and is well known, and has a long history, make the region's traditional architectural form and style formed with strong local characteristics, so the author choose the traditional ancestral temple buildings in the region as the research object. First we collected basic information such as traditional architecture, historical culture and so on in Ji 'an Region! Secondly, field research method was adopted to survey data, image collection and related drawings of radio and TV Traditional ancestral temple buildings, including analysis of the architecture form, decorative art and style type of Heading Radio and TV Temple. Finally, through systematic study and comparison of these two representative ancestral temples, objective conclusions of architectural art characteristics are drawn. At the same time, this paper will enhance people's understanding of traditional architecture culture and traditional aesthetic influences of Genui And TV ancient villages, and provide reference for heading research on the transmission of traditional architecture and art in $\mathrm{Ji}$ 'an region and carrying forward national culture.
\end{abstract}

Keywords: Ji 'an region, Traditional architecture, Architectural form, The art analysis

\section{江西吉安渼陂村传统祠堂民居艺术解析}

\author{
李琰君 ${ }^{1, \mathrm{a}}$, 孙幸之 $2, \mathrm{~b}^{*}$
}

\footnotetext{
1 陕西科技大学，西安，710021

2 西安理工大学, 西安, 710054

aylw55668@163.com

b*645390865@qq.com
}

\section{摘要}

江西省吉安地区的传统建筑以其风格古朴、端庄大气、层次分明、错落有致、结构精巧、雕梁画栋而被世人熟 知, 加之具有悠久的历史, 使本地区传统建筑形态和艺术风格形成了具有浓郁的地域特色, 故笔者选择了本地 区的传统祠堂建筑作为研究对象。首先汇集了吉安地区渼陂古村中传统建筑、历史文化等基础资料; 其次采用 了田野调研法对渼陂古村中传统祠堂建筑进行了数据测量、图像采集和相关图纸绘制，包括对“永慕堂”、“求 志堂”等的建筑形态、装饰艺术及风格类型进行分析; 最后以艺术类学理论对这具有代表性的祠堂进行了较为 系统地分析、比较和研究, 并得出较为客观的祠堂建筑艺术特色结论。同时, 通过本文的研究和交流增强人们 对渼陂古村中传统建筑文化的了解和审美熏陶, 也为进一步研究吉安传统民居建筑与艺术以及传承和弘扬传 统民族文化提供参考。

关键词: 江西吉安; 传统建筑; 建筑形态; 艺术解析 


\section{1.引言}

江西省吉安市曾经有庐陵的美称，又名“江南望 郡”。清代以前社会经济和人文发展繁荣昌盛, 逐渐构 成了璀骤的“庐陵文化”。因此，庐陵文化是江西省文 化的重要支撑，具有着深厚悠久的文明历史。由于庐 陵文化对于当地的影响, 吉安地区目前仍然保留着丰 富的古村落与古建筑群, 每个古村中有大量的高等级 祠堂和合院式的民居院落, 其中最为耀眼的莫过于宗 祠建筑了。宗祠文化受到庐陵文化、传统礼制文

化和家族文化的影响, 并传承和反映出了吉安地 区本地的建筑文化底蕴。有明清时期, 江右帮、晋帮 和徽帮是中国的三大商帮, 其中的江右帮回到家乡重 建故居, 为吉安地区古村落建筑修建奠定了坚实的物 质和技术支撑 ${ }^{[1]}$ 。

\section{2.吉安渼陂古村传统建筑概况}

吉安地区的古村落大多置于赣西南地区，古村中 的传统建筑均为赣式民居建筑的样式, 而渼陂古村作 为江西省内历史文化名村的其中之一有着“文化第一 村”的盛名，古村距今历史已有 870 多年，在近代历 史中还是中央苏区建设的前沿发源地 ${ }^{[2]}$ 。渼陂古村坐 落于吉安市青原区富水河的西部, 紧靠西北方向绵延 的山脉, 与东边的富水河相接, 南部远眺重峦叠嶂, 古村则置于其中的平川之上。作为吉安地区十分典型 的历史文化名村, 其中的传统古建筑也含有其他地区 缺少的建筑特色。因此, 本文将本村的祠堂民居从村 域分布、建筑形制、建筑艺术、装饰特色诸方面来分 析渼陂古村中的传统建筑形态特征(图 1)。

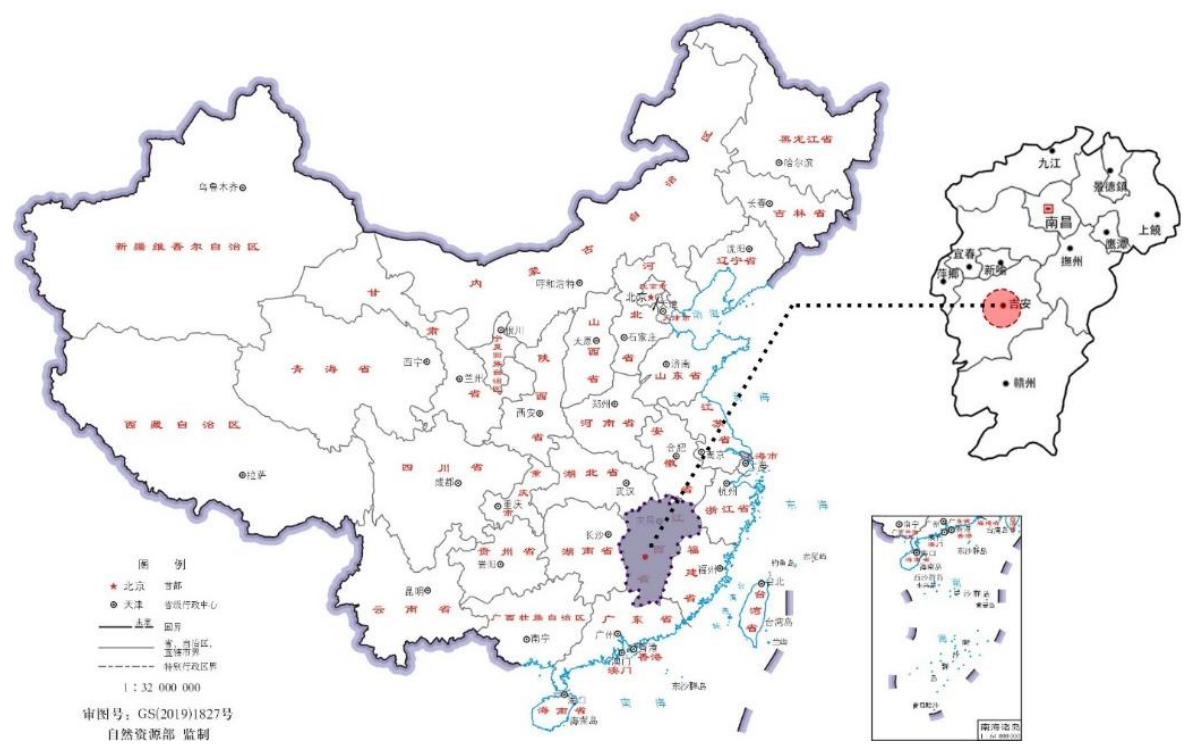

图 1 吉安渼陂古村区位图

（图片来源：源于国家基础地理信息中心，笔者改绘）

\section{1.祠堂的村域分布}

根据史料查询和文献记载得知, 以前居住在渼陂 古村中的村民大多都是江右民系，村中有 300 多栋保 存较为完整的传统古建筑, 古村的平面呈现为前村后 街形态, 建筑整体布局虽然参差不齐, 但是细看却有 条不紊, 村中的巷道呈八卦状分布, 街道路面以卵石 装饰, 村内被 28 个水池围绕, 取自二十八星宿之意 [3]。古村中部分古建筑在明朝正德年间（约公元 1519 年）被重建，在清朝时期又加以改造，所以村中大部 分建筑包含了明清两个时期的风格, 宗祠的建筑形态 和装饰艺术语言非常丰富, 祠中有许多传承下来的家 训和精致无比的雕刻。在 20 世纪 30 年代, 赣西南苏 维埃政府和江西省苏维埃政府在此成立, 到目前为止, 这里还保存着很多的红色革命旧址, 如: 二七会议旧 址、曾山旧居和毛泽东旧居等。改革开放后, 当地居 民在修莫古建筑时把现代建筑艺术风格与原有建筑
加以糅合, 使经过改造的建筑与其他古建筑风格大相 径庭。至今还有很多村民在此居住，古建筑也保存的 相对完整，这也为实地调研考察供应了较为完整的第 一手资料 ${ }^{[4]}$ 。

\section{2. 祠堂建筑的形制}

渼陂古村中有一个总宗祠保存较为完整，为“梁 氏宗祠”。梁氏总宗祠在南宋时期开始建立, 元末时期 被毁，在明朝正德年间又重新修建。根据以前的宗族 文化，“总祠”和“房祠”的形制各有特色，总祠一般是 古村中院落和建筑体量最大并且装饰最丰富的, 均为 五开间, 三进式双天井的结构形式，祠堂基本由门厅、 享堂和寝堂构成, 房间是沿着轴线分布排列, 三进建 筑间的左右两边设有厢廊，一般第二进为厢房，所以 整体形成了前后两个天井院落的布局。门厅一般是五 开间，其中三开间后面会建成门廊，中门的尺寸明显 
大于两侧，其余两开间被石墙封锁。享堂是以前村民 举办仪式的活动场地, 其中的三开间都是开放的, 寝 堂是放置祖先灵牌的房舍, 中部开间开放 ${ }^{[5]}$ 。另外, 在古村中也存在一些没有享堂的祠堂，总体被称作 “房祠”，也有部分祠堂没有门户、享堂和寝堂的被称 作“家祠”。

\section{3. 祠堂的建筑艺术}

渼陂古村里的祠堂建筑分为木构架和砖木混合 两种结构体系，高等级的祠堂一般采用木构架，而像 家祠这类等级较低的祠堂更多使用砖木混合体系。祠 堂中木构架体系为穿斗式构架, 局部会结合穿斗结构 和抬梁结构的特点来建造, 由于吉安地区空气湿润, 木质结构比较容易受潮腐烂, 利用穿斗式结构可以方 便后期进行保护和替换建筑构件, 其次, 穿斗式建筑 的木构件材料相对于其他材料更为便宜, 可以节省建 造费用 ${ }^{[6]}$ 。

古村中祠堂均为硬山屋顶, 飞檐趐角, 祠堂屋面 的装饰重点基本都放在木构牌楼和内部抱厦的屋顶 上, 其屋脊的装饰十分精致, 两边的泥塑雕刻的栩栩 如生, 祠堂外山墙上也绘有精美的图案, 屋檐下的水 墨画被称为檐画, 古村中各等级的祠堂建筑均绘有檐 画, 绘画多数为传统山水画风格, 内容多以山水和日 常生活为主题绘制, 并在两端题有诗文, 绘制檐画成 为当时族人们抒发情感的事物 (图 2)。祠堂内部抱厦 为歇山式屋顶, 享堂的檐口会设计的比下厅高一些, 屋檐下的装饰图案多以花卉和动物为主, 整体呈现出 简洁质朴, 端庄大气的建筑风格。

古村中建筑的天井也很有当地的建造特色, 在明 清时期, 祠堂内堂中央均用青石板建造成回形的水渠, 并且在周边设有护栏, 当雨季来临时, 降水量激增, 雨水从屋檐滴落进天井中的水渠, 古人认为将雨水收 集可以寓意聚财, 有“四水归堂”之说。同时, 天井也 有采光、遮阳、通风的功能, 在渼陂祠堂建筑中占据 重要的位置。

\section{4. 祠堂的装饰特色}

渼陂古村中的建筑装饰融合了当时的审美思想 和民俗文化, 装饰图案种类多元, 做工精巧。内容多 采用民间故事、神话历史等题材, 较好地把实用与艺 术完美结合。如在宗祠的堂顶都有精致的藻井装饰图 形 (图 3), 配合藻井和轩蓬结构进行顶部装饰, 形成 较为固定的鹤颈和船篷等样式, 正堂中间通常使用藻 井天花, 呈现出正堂在整体格局中的重要性和地位 ${ }^{[7]}$ 。 祠堂外门的门仪基本使用红石门仪, 少数则会使用木 制或青石等材料, 侧门门罩上刻有诗句, 并加以少许 装饰 ${ }^{[8]}$ 。

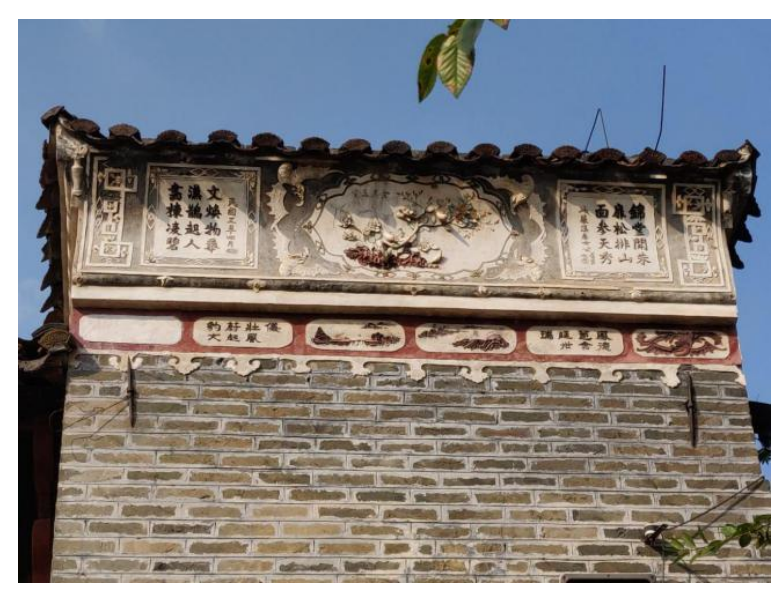

图 2 永慕堂檐画

（图片来源：笔者自摄）

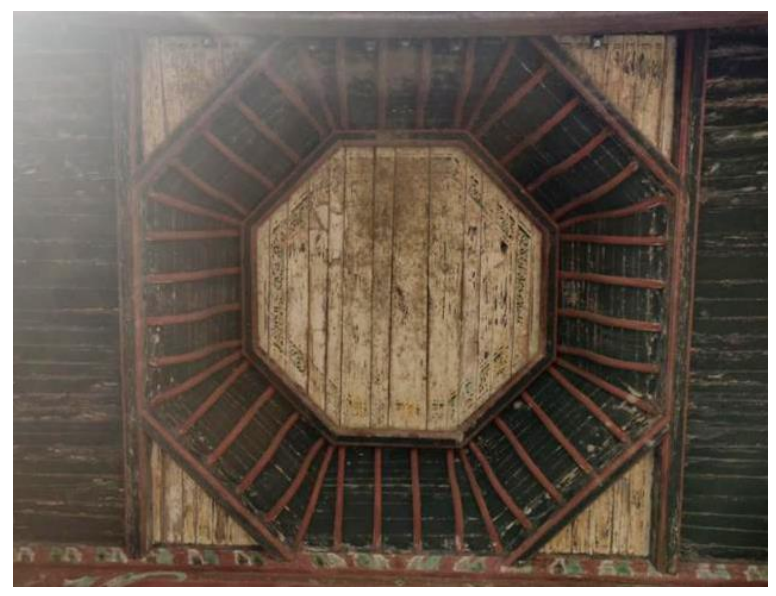

图 3 永慕堂藻井

（图片来源：笔者自摄）

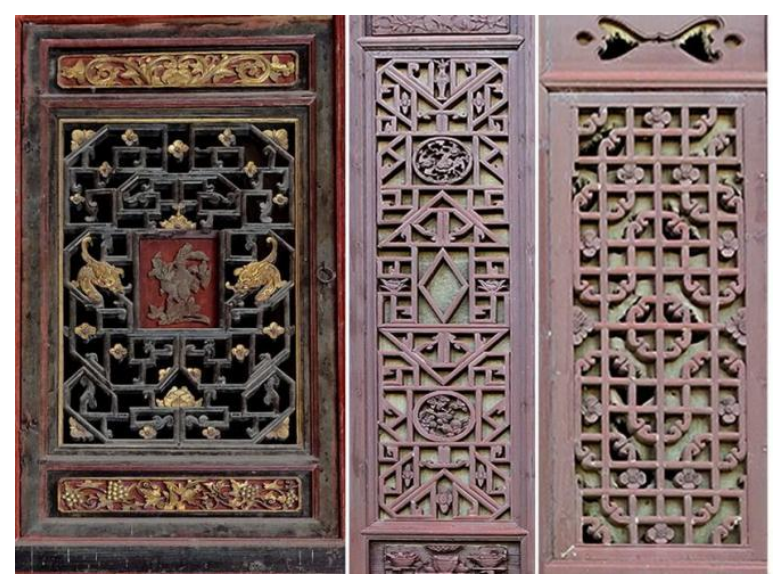

图 4 槅扇

（图片来源：笔者自摄） 

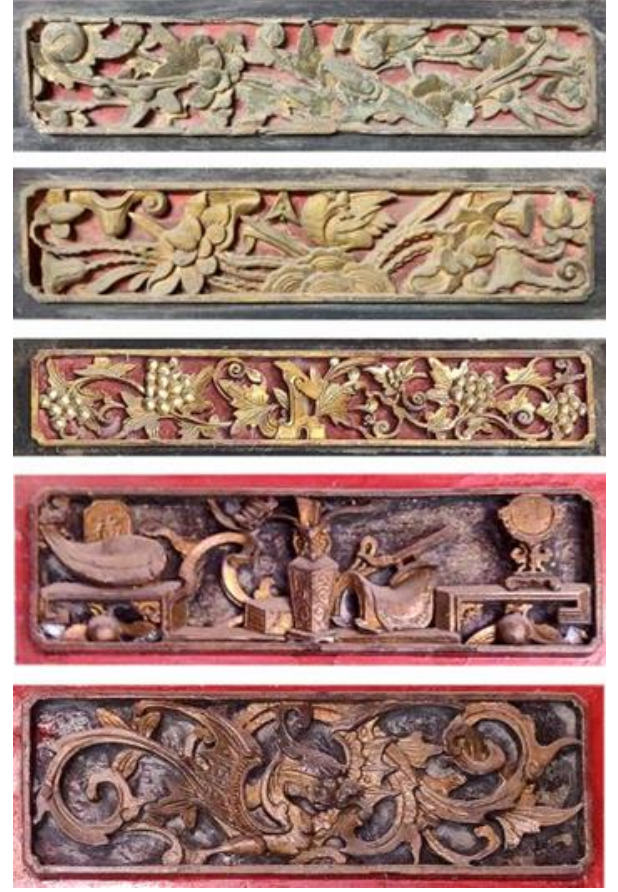

图 5 槅扇涤环板

(图片来源：笔者自摄）

渼陂的民居和其它地区一样比较侧重门楣和前 厅的修饰, 大多数是单楼门罩, 房屋的飞檐设计精致 巧妙, 室内顶面多用藻井装饰, 有八卦状、长方状、 方形状等, 周边会用彩绘加以装饰, 部分装饰材料使 用石灰、桐油和糯米水制作而成, 可以使其不易腐坏, 保存时间更长。当地因十分重视建筑内门窗的装饰, 所以会在槅扇上雕刻精致的图案, 槅扇最高可达到 3 米, 每个槅扇均有精致的透雕, 部分还会镶嵌上花鸟 图案, 一列槅扇组成大型的屏风, 彰显出古朴雅致的 氛围 (图 4)。槅心两端的涤环板做工也十分精细, 常 以花草、祥离瑞兽和神话故事等为主题加以雕刻（图 5 )。檐坊上常会有描金圆雕、浮雕或线雕, 房内上方 的木雕花板会使用浮雕手法来体现花鸟和历史人物, 还有些会刻上家训、对联、诗句等, 这些精致的壁画 和雕刻的对联、诗句等使渼陂古建筑装饰内容更加丰 富多彩, 在艺术表现语言上锦上添花。

\section{3.渼陂古村传统建筑形态分析}

本文通过实地调研与分析, 把古村中最具备代表 性的古建筑群中挑选了两种不同类型的祠堂建筑, 即 永慕堂 (梁氏宗祠) 和求志堂 (轩公祠) 为研究对象。 希望通过分析这两种不同类型的古建筑，让大众对渼 陂古村的建筑文化有更深层次的理解和更全面的认 识。

\section{1.永慕堂—梁氏宗祠}

永慕堂又称“梁氏宗祠”、“渼陂永慕堂祠”, 属于 “总祠”类, 2006 年 12 月 18 日被江西省人民政府列为 江西省文物保护单位。该宗祠始建于南宋初年 (约公 元 1127 年), 元末时期被毁, 在明朝正德年间（约公 元 1519 年）重新修建, 距今已有 800 多年的历史, 曾在国共内战时期为红四军军部原址。

永慕堂在宋代开始修建, 之后许多古建筑因为战 争被大肆破坏,随着历史的发展, 经过几次的重修扩建 蜕变成如今的梁氏宗祠 ${ }^{[9]}$ 。总占地面积 1125 平方米, 坐北朝南, 面阔五间, 进深 57.7 米的天井式格局。其 形制组成分为: 门廊、下厅、参亭、享堂和寝堂。门 屋进深 5 米, 宗祠内享堂占地面积最大(图 6)。

永慕堂大门位于南边, 门廊结构为五开间, 左右 两开间为暗面用房, 砖体墙加以修筑, 中部三开间为 门廊入口, 整体用一道厚石墙将内部和外部空间相隔 开, 并在石墙上分别業开三个门洞, 大门设计在石墙 正中的位置 (图 7), 祠堂大门宽 1.4 米, 两个侧门宽 1.2 米, 高 3 米。中间大门比其他侧门尺寸略宽。大 门上黑色石板匾额上刻有“梁氏宗祠”, 两侧门上方分 别题有“仁型”和“讲让”的书法字样，体现了儒家文化 思想。入口处两侧对称置有抱鼓和石狮, 抱鼓、石狮 和门䙃都是以红砂岩石为材料, 红砂岩石没有青石坚 固, 更方便工匠们雕刻精致的图案。门廊上方有一木 构牌楼 (图 8), 牌楼上写有 “翰林第”三个大字, 以此 鼓励族人勤勉学习, 耕读持家, 光宗耀祖。牌楼为官 帽式结构, 屋顶下面每一个圆形镂空的装饰翼板上都 雕刻有文字和图案, 木牌楼下两根八角形红砂岩石柱 上还刻有对联。门廊上面还搭建了天花藻井, 藻井中 的绘画堪称一绝，用传统的中国画形式把人物以及花 草树木描绘的栩树如生, 把历史故事通过绘画真实的 展现出来, 描述了当时太平盛世的景象。柱础基本由 红砂石建造, 平面为八角形, 部分刻有精致的图案。 


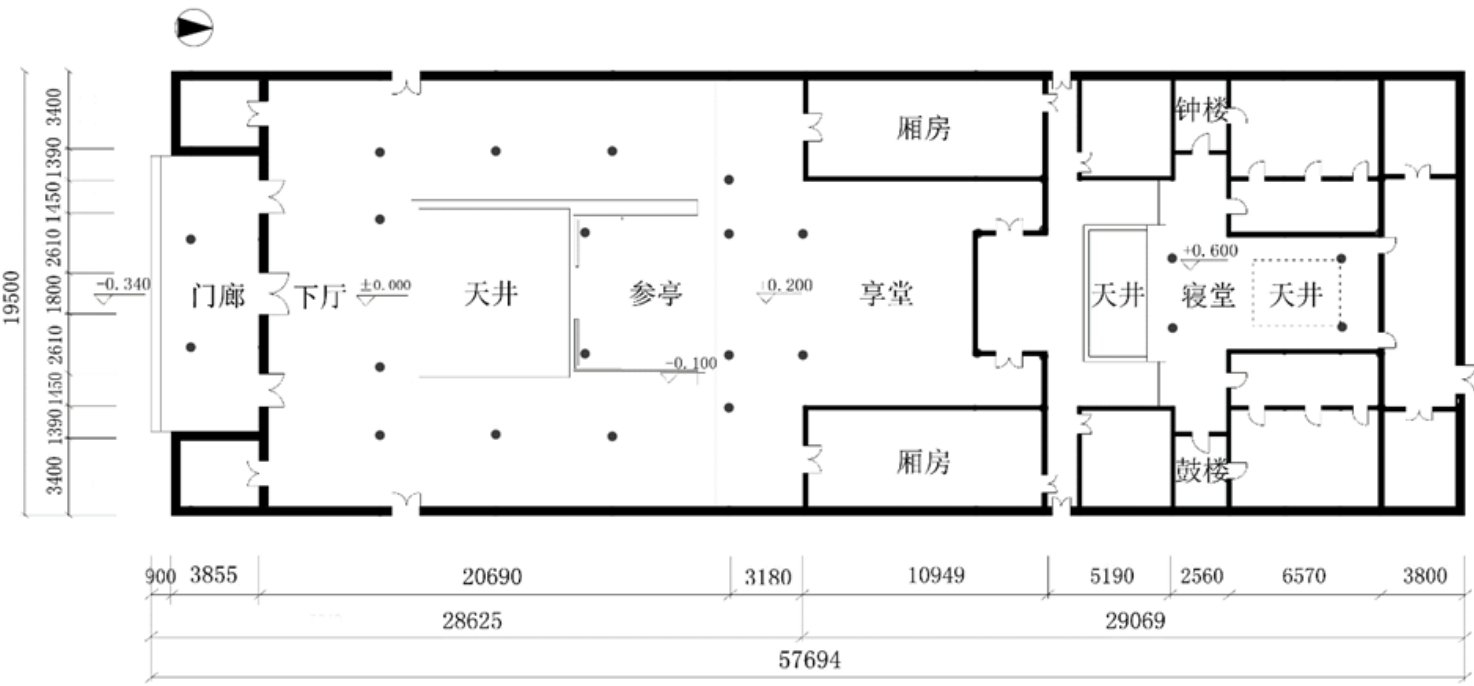

图 6 梁氏宗祠平面图

（图片来源：笔者自绘）

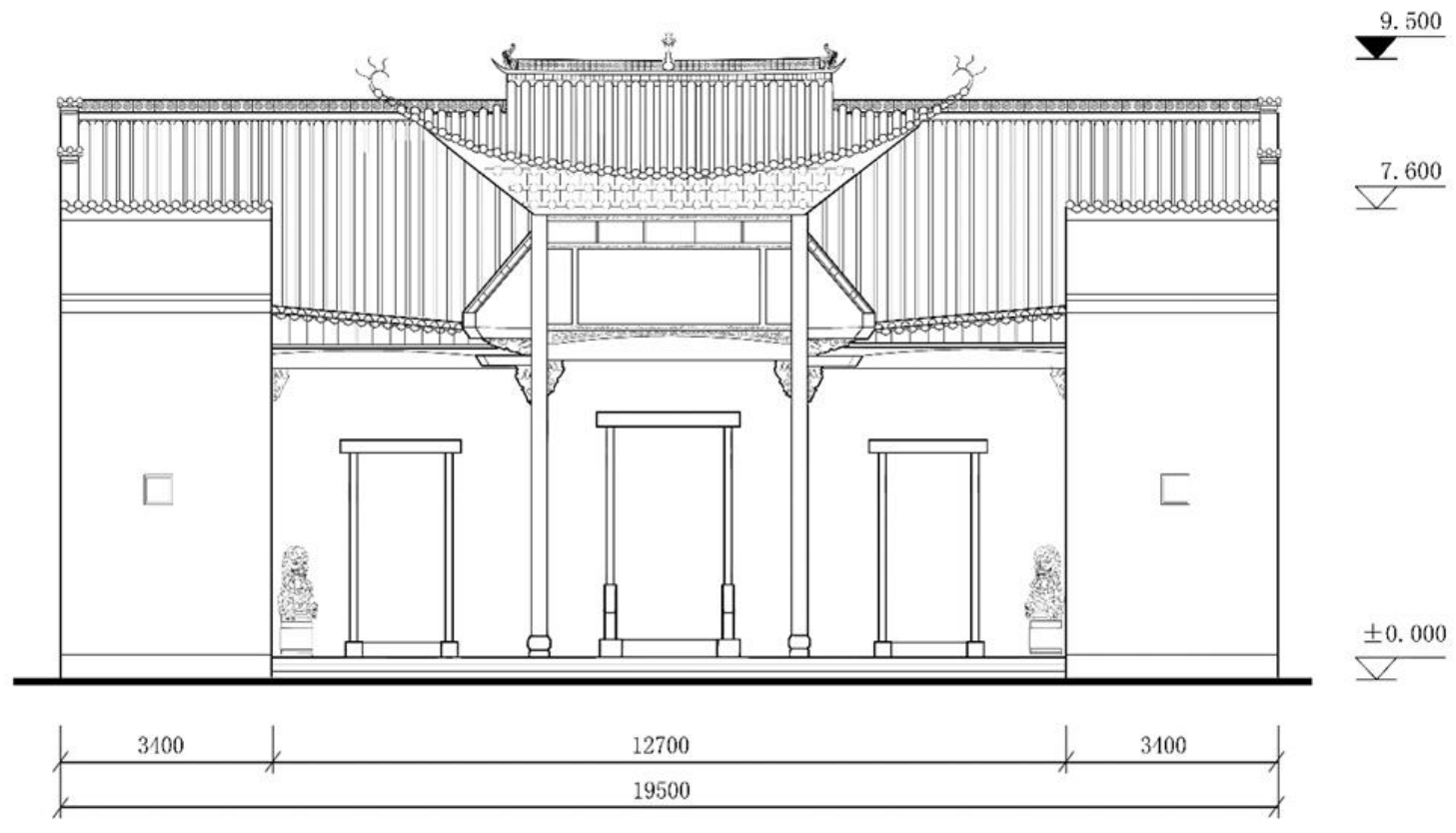

图 7 永慕堂南大门立面图

（图片来源：笔者自绘）

当通过大门, 进入下厅后视野开阔, 下厅与内部 享堂连为一体，使得天井显得空间更加宽阔，堂中的 抱厦伸向天井, 堂前为四角亭, 参亭使用的是双层坡 屋面，下层的吊顶使用了樟木并用红漆涂刷以营造端 庄、大气、严肃的氛围, 檐柱和门墙间建有藻井 (图 9), 梁架为穿斗式构架, 砌上明造使梁架结构暴露在 外, 梁柱的尺寸较小, 基本为月梁。地面主要使用鹅 卵石和青石板铺装, 在堂前中央设置有一米深的方形 蓄水池, 并在周围构置有石质栏杆。

享堂前的抱厦建筑为参亭 (图 10), 前檐正中上
挂有“教授”的牌匾，左右分别挂着“文元”、“登科”的 小型牌匾，柱子上刻有对联，周围的石柱栏杆上也刻 有精美的图案，轩梁也为月梁的样式，并刻有龙凤主 题的装饰图案。作为祠堂第一进的中心地区, 参亭可 以在本族人商议大事时容纳下更多的族人。在四周墙 上题有“忠”“敬”“信”“笃”四个家训大字, 这是梁氏祖 先北宋时期在此立足时, 就把“忠、信、笃、敬”四个 字立为祖训。两旁侧门上方牌坊刻有“入则孝”和“出 则弟”, 告诫后人遵守道德规矩。

享堂为五开间, 三明两暗, 两侧房间用来储藏物 
品不对外开放, 作为举办祭祀仪式的堂屋, 享堂内部 装饰最为精致, 梁架使用砌上明造, 屋顶和下厅都使 用重檐屋顶的方法, 享堂的檐口比下厅高一些, 下层 的吊顶均为红漆涂刷，轩梁上刻有龙风主题的装饰图 案, 由于清朝时期建筑装饰十分华丽, 祠堂内的装饰 构件雕刻的十分复杂，格外注重装饰手法，令装饰内 容充满更多的人文思想，表达出当时村民对美好生活 的追求与向往。

寝堂前木构牌楼由两部分组成, 上部为独立的歇 山顶, 下部和屋面的檐口平齐, 平面上建成倒八字的 形状, 中间斗拱上放置了很多精致镂空的装饰圆板, 还刻有文字。牌楼上题有“对越在天”, 寓意鞭策后人 言行举止要无愧于天地, 谨言慎行, 牌楼整体装饰和 大门处牌楼一样精致 (图 11)。

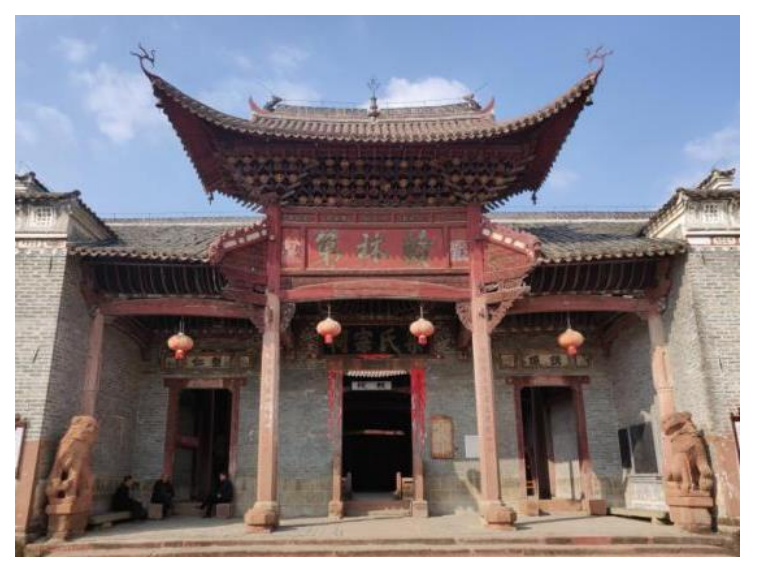

图 8 永慕堂南大门木牌楼

（图片来源：笔者自摄）

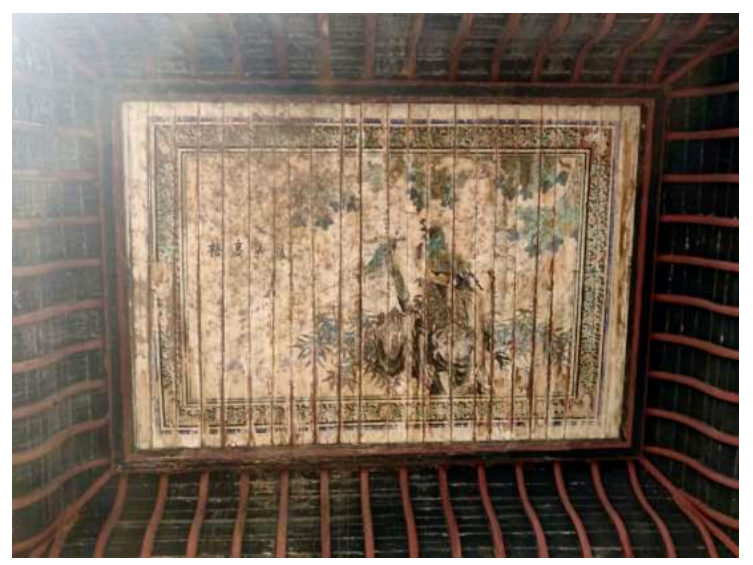

图 9 永慕堂藻井

（图片来源：笔者自摄）
寝堂中间是举行祭祀仪式的开敞空间，顶部为八 角形双层藻井天花, 檐柱间有一条两米的檐廊, 檐廊 都采用轩蓬, 两侧分别是钟楼和鼓楼, 所有的装饰集 中在木牌楼和轩蓬顶。享堂两侧厢房的外廊与钟鼓楼 相连, 以前是给举行祭祀参拜时女眷的活动空间。

\section{2. 求志堂——轩公祠}

求志堂又称“轩公祠”，属于“房祠”类。同样于 2006 年被省政府列为江西省文物保护单位, 是渼陂古 村中目前保存比较完整的房祠, 一般房祠的等级比总 祠低, 所以总祠的地位和规格会比房祠大, 一般的房 祠对比总祠来说都没有享堂, 因此, 房祠的面积会比 总祠小一些 $[10]$ 。求志堂修于清代光绪二十一年 (约公 元 1895 年), 距今已有 125 年的历史。

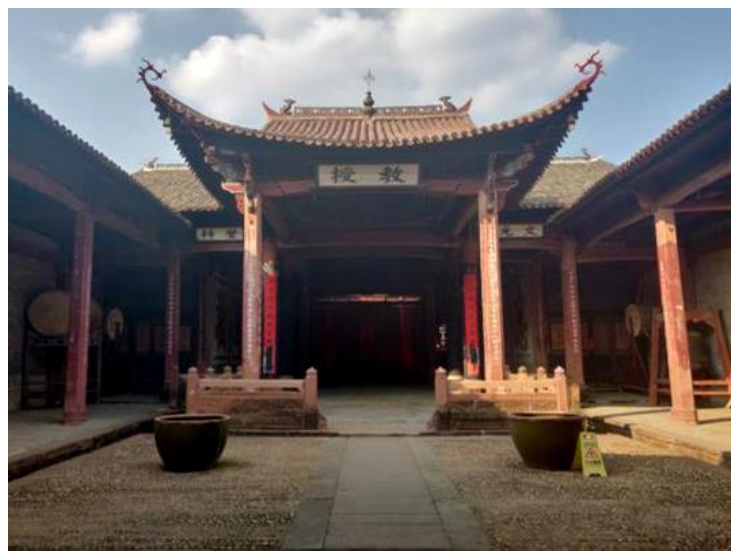

图 10 永慕堂参厅

（图片来源：笔者自摄）

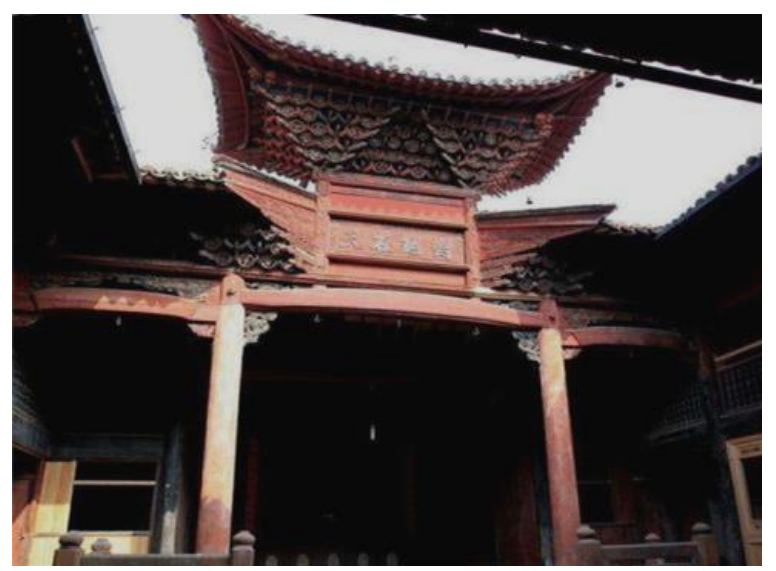

图 11 享堂木牌楼

（图片来源：笔者自摄） 


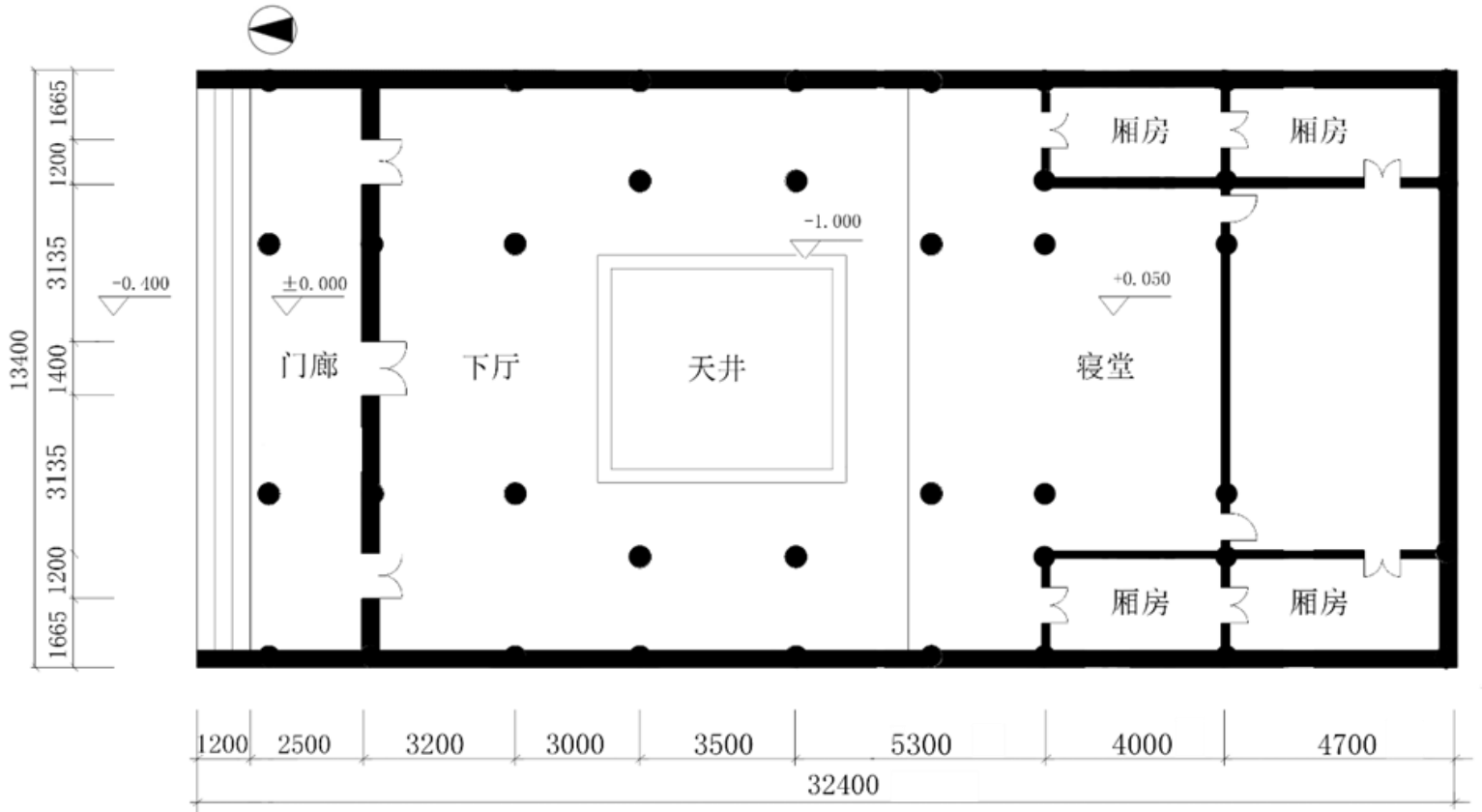

图 12 求志堂平面图

（图片来源：笔者自绘）

该房祠坐北朝南, 长 32.4 米, 宽 13.4 米, 总占 地面积 434 平方米，为面阔三间，两进深的天井式祠 堂，其形制组成分为: 门廊、下厅和寝堂。整体平面 呈长方形，下厅的占地面积最大 (图 12)。

求志堂大门位于古村 216 号, 入口处是三开间的 门廊，对比梁氏宗祠的门廊少了两侧的暗间，屋顶的 高度和总祠高度差不多, 使求志堂的门廊同样显得更 庄重典雅，在等级上也似乎不逊色于宗祠。在建筑两 侧使用了具有赣派建筑特色的马头墙, 屋顶为单坡式 硬山屋顶, 坡度平缓, 梁架结构相对简单, 门廊的梁 柱为穿斗式结构, 梁柱同样采用传统红漆涂刷, 檐梁 为月梁的样式, 雀替雕刻成镂空的样式。在顶上方的 藻井绘有很多精美的彩画。整个大门为用砖墙修筑, 中间大门比其他尺寸略大, 中门宽 1.4 米, 侧门宽 1.2 米, 高 3 米 (图 13)。门框用红砂岩石镶嵌, 刻有金 色楹联, 为嵌字联, 上联第一个字为“轩”, 下联则是 “公”，永慕堂的很多楹联都是嵌字联，大门两侧对称 设置有抱鼓石, 也是用红砂岩石作为材料, 且在抱鼓 石雕刻有精致的花纹。在大门额枋上的青石匾额上刻 有“轩公祠”三个大字, 显得十分庄重大气, 侧门的门 匾上题有“叙伦”和“修纪”的字样, 体现出本族的先祖 们对祠堂的敬意和对后辈们的传承期望。

进入下厅后，整体空间相对开阔，天井尺寸明显 比永慕堂小, 天井下方地面也设有一米深的方形排水 沟, 下厅内部装饰较为简单, 柱子基本为方形石柱, 柱子直径比总祠的细一些, 由于江西常年下雨导致气 候湿润，所以柱础都制作成三十厘米左右的高度来防 止柱子损坏，红石柱础之上雕刻有花纹进行装饰，额
枋上的梁架与其他总祠一样为穿斗式结构, 地面基本 都是用石砖铺砌（图 14）。

寝堂为开敞空间，是用来安放祖先灵牌位的空间， 顶部藻井绘有巨型彩绘分别是《百老图》和《百少图》, 被称为渼陂的镇村之宝，体现了族人追求国泰民安的 美好愿望。堂中正上方挂有木质徧额, 题有“求志堂” 三个大字，徧额后的横梁做成镂空的样式，下方安置 了一排镂空的屏风, 上面刻着镂空的花卉纹样, 寝堂 两侧用石墙分别隔开一个小房间，房门尺寸较小，宽 度约 1 米, 房间平面布局沿中轴线对称, 一般作为服 务用房（图 15)。

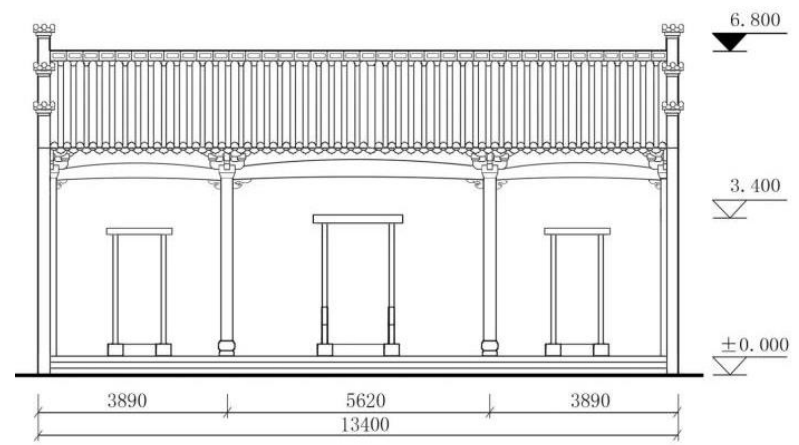

图 13 求志堂立面图

（图片来源：笔者自绘） 


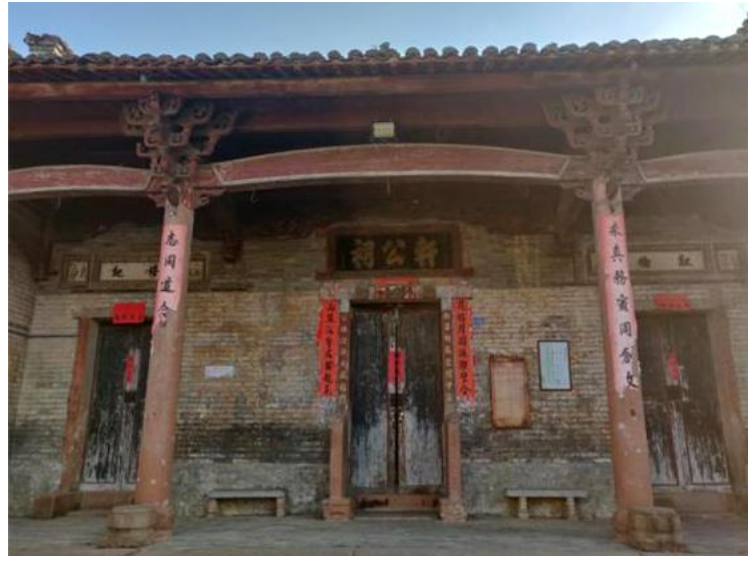

图 14 求志堂正门

（图片来源：笔者自摄）

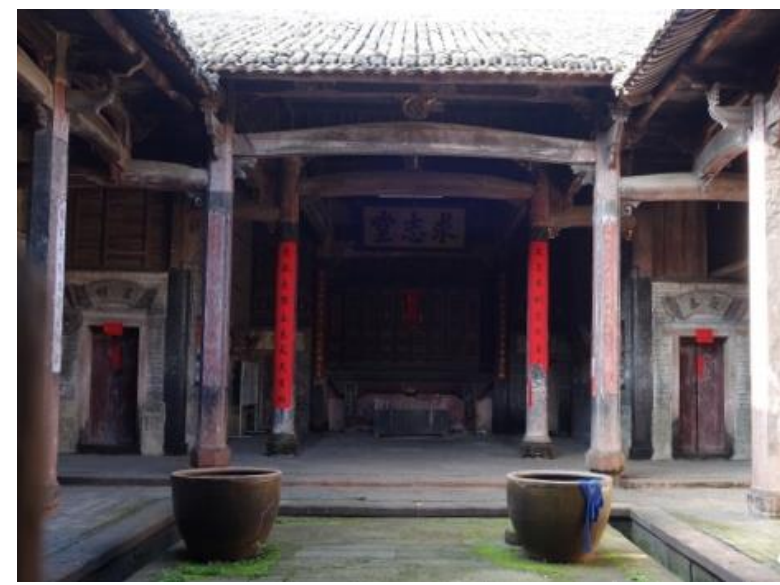

图 15 求志堂下厅

（图片来源：笔者自摄）

\section{4.结论}

在传统的礼制文化、宗族制度和庐陵文化的影响 下, 渼陂古村中的宗祠在平面形制、构造及装饰工艺 上有着与众不同的风格, 宗族制度也将各建筑间的布 局相互约束 ${ }^{[11]}$ 。但在建筑形式和装饰艺术上都呈现出 十分浓厚的地域文化, 当地宗祠建筑在庐陵文化的影 响下彰显出古朴雅致的风格, 在祠堂的建筑结构上也 呈现出有着严格的等级制度。总祠在院落和建筑体量 上高大, 以显示地位, 在建筑装饰上也十分丰富华丽, 同样展示出至高无上的地位。这些典型建筑形式体现 了渼陂古村在当地建筑文化中有着无可取代的位置, 形成了属于渼陂古村特有的建筑风格, 充足展现了渼 陂千百年来广为流传的民俗文化、建筑文化范式和区 域审美习惯, 而这些文化和现象也是“庐陵文化”的重 要组成部分 ${ }^{[12]}$ 。

\section{项目基金}

国家社科基金艺术学重点项目：陆路“丝綢之路”
境内段中国传统民居建筑艺术及民俗文化研究

(项目编号:18AH008)阶段性成果。

\section{REFERENCES}

[1] Local Records Compilation Committee of Jizhou District, Ji 'an City, Jiangxi Province. Records of Ji 'an City (1990-2000) [M]. Jiangxi People's Publishing, Nanchang.

[2] Li Yanjun. (2011) Traditional residential buildings and residential folk culture in Guanzhong, Shaanxi Province. Science Press, Beijing.

[3] Huang Hao. (2008) Jiangxi dwellings.China Building Industry Press, Beijing.

[4] Yu Jiping. (2010) Research on the Architectural Art of Clubhouse in Wujiang River Basin [J]. Contention of Literature and Art, 22:100-106.

[5] Zhang Dong. (2014) Study on the Optimization of Public Space in the Ancient Village of Huibei Based on Tourism Development [D]. Central South University of Forestry and Technology.

[6] Du Haiming. (2009) Study on the Protection and Utilization Value of Huibei Ancient Village in Ji 'an [D]. Nanchang University.

[7] Li Ji. (2018) Study on Passive Design Method of Jiangxi Traditional Patio Residence [D]. Beijing University of Technology.

[8] Zhou Yongmin, Zhang Ling. (2010) Aesthetic Features of Traditional Woodcarving Pattern Art in Wuyuan [J]. National Art, 02:91-93.

[9] Liang Changjun. (2005) Analysis of Hakka Architectural Culture [J]. Literary Contention, 06:134-137.

[10] Zhu Xuemei. (2013) Study on the Form and Architectural Characteristics of Traditional Villages inNorthern Guangdong [D]. South China University of Technology.

[11] Hu Ying, Li Tian. (2018) Research on Architectural Structure and Decorative Art of Jiangxi Ancient Dwellings — Taking Wangshan Tuku as an example [J]. China National Expo, 10:209-211.

[12] Christian Chou. (2010) New local dwellings and regionality in Ji 'an, Jiangxi [D]. Central Academy of Fine Arts. 